\title{
Numerical Analysis of Super-Tall Buildings with Replaceable Members
}

\author{
Wenyan Shan ${ }^{1, a}$, Yun Chen ${ }^{1, b^{*}}$ \\ ${ }^{1}$ College of Civil Engineering and Architecture, Hainan University, Haikou 570228 , China \\ a6602075@qq.com, bchenyunhappy@163.com
}

Keywords: replaceable members; numerical analysis; super tall buildings

Abstract. The concept of installing energy dissipation devices in a coupling beam of shear wall structures has been proposed and investigated. The energy dissipation device is used to dissipate seismic energy and is easy to be replaced in the post-earthquake event. According to the practical design methods of replaceable coupling beams, some selected conventional coupling beams installed replaceable energy dissipation devices. Two bench-mark models are built in ABAQUS program, one with conventional coupling beams (CBM model) while the other with replaceable coupling beams (NBM model). Modal analysis, response spectrum and earthquake time-history analysis are conducted to verify the advantage of replaceable coupling beams. It was found that the inter-story drift angle and damage of the NBM model was smaller than CBM model. Moreover, the damage of the replaceable coupling beams mainly concentrated in energy dissipation devices, while the other parts of replaceable coupling beams kept intact. In contrast, the conventional coupling beams produced irreversible damage, which is more difficult to restore after earthquake.

\section{Introduction}

Coupled shear wall structures are often employed as efficient lateral-force-resisting-systems in tall buildings. However, because of some architectural requirements, typical coupling beams are usually of small span-to-depth ratios. This often renders conventional RC coupling beams producing brittle failures in the form of diagonal cracking and sliding cracking are usually encountered under strong earthquakes [1]. Recently, the concept of replaceable structural member is proposed to achieve earthquake resilient structural design[2-5]. A replaceable energy dissipation device is usually installed in the middle of a coupling beam. The device not only can dissipate seismic energy, but also it can be easily replaced and restored immediately after an earthquake. In this anticle, the seismic performance of super tall buildings with replaceable coupling beams will be comprehensively investigated through modal analysis and time history analysis, and some interesting conclusions can be obtained.

\section{Analysis Model}

According to previous studies[5], we have proposed a practical design method for replaceable coupling beams. The design principle is that the conventional coupling beams and the replaceable coupling beams would exert identical constrained moment to the wall limbs. Consequently, a super-tall benchmark model installed with replaceable coupling beams was established, named NBM, and the same model but with conventional coupling beams was also established, named CBM. A total height of the benchmark model is $226.5 \mathrm{~m}$. The structural system is steel frame-RC core tube. Fig. 1 shows the typical plan layouts of the model. The fuse resembles a segment of $\mathrm{H}$ shaped steel but with two steel webs, where filling with lead between webs. The seismic behavior of replaceable fuse has been studied in previous research[6]. The fuse demonstrated steady and full hysteretic curves.

In order to acquire the amount and location of replaceable coupling beams that should be set, the response spectrum analysis for the CBM was conducted. The results is that the stress and strain of coupling beams located between 11th storey to 30th storey are larger than any other stories. Meanwhile, considering that it is not economic to substute for all conventional coupling beams. We select 280 coupling beams to be replaced as replaceable coupling beams shown in Fig. 2 


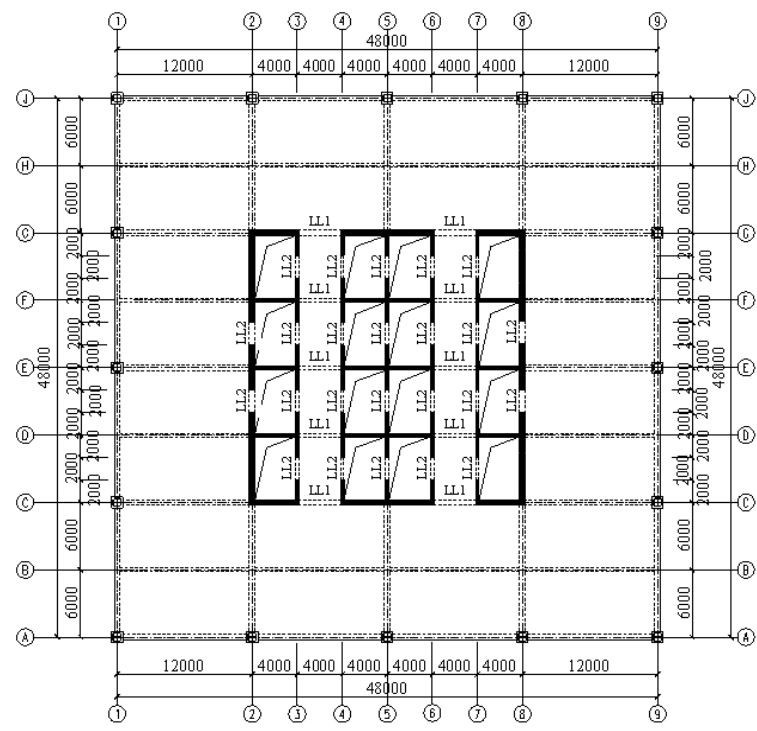

Fig.1. Typical plan layouts of the model

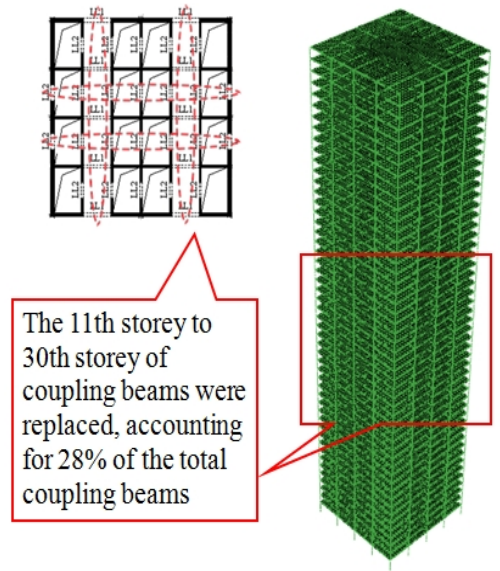

Fig. 2. Replaceable coupling beams

\section{Modal Analysis}

Table 1 shows the modal comparison results of two models. It can be seen from the table that the $\mathrm{CBM}$ and NBM have the similar vibration mode. The natural vibration period of NBM is a little higher than that of CBM. The reason is that although the replaceable coupling beams and conventional coupling beams can undertake identical shear force, the cross-sectional dimension of conventional coupling beams are larger than that of replaceable couplig beams. Hence, the stiffness of replaceable couplig beams are less than that of conventional coupling beams. This also indicated that replaceable coupling beams can cause a little stiffness reduction of structure, but the difference is small. Under frequent earthquake, the NBM can also satisfy the seismic requirement of Chinese seismic code.

Table 1. Modal comparison of two structures

\begin{tabular}{|c|c|c|c|c|c|}
\hline $\begin{array}{c}\text { Vibration } \\
\text { model }\end{array}$ & \multicolumn{2}{|c|}{ Period(s) } & \multirow{2}{*}{ Translational factor $(\mathrm{X}+\mathrm{Y})$} & $\begin{array}{c}\text { Torsion } \\
\text { coefficient }\end{array}$ & Difference (\%) \\
\cline { 2 - 3 } & CBM & NBM & & 0 & 4.25 \\
\hline 1 & 4.968 & 5.179 & $1.00(1.00+0.00)$ & 0 & 2.59 \\
\hline 2 & 4.711 & 4.833 & $1.00(0.00+1.00)$ & 1 & 7.97 \\
\hline 3 & 3.902 & 4.213 & $0.00(0.00+0.00)$ & 0 & 2.38 \\
\hline 4 & 1.470 & 1.505 & $1.00(1.00+0.00)$ & 1 & 2.19 \\
\hline 5 & 1.372 & 1.402 & $0.00(0.00+0.00)$ & 0 & 2.26 \\
\hline 6 & 1.326 & 1.356 & $1.00(0.00+1.00)$ & 0 & 3.66 \\
\hline 7 & 0.793 & 0.822 & $1.00(1.00+0.00)$ & 1 & 3.90 \\
\hline 8 & 0.718 & 0.746 & $0.00(0.00+0.00)$ & 0 & 4.31 \\
\hline 9 & 0.649 & 0.677 & $1.00(0.00+1.00)$ & 0 & 3.05 \\
\hline 10 & 0.525 & 0.541 & $1.00(1.00+0.00)$ & & \\
\hline
\end{tabular}

\section{Earthquake Time History Analysis}

Time-history analysis is carried out for the two models under rare earthquakes (2-3\% exceeding probability in 50 years). A total of five earthquake waves are used as input earthquake waves in the analysis shown in Table 2. The earthquake waves were input into structure in dual direction (X direction: Y direction=1:0.85). The peak accleration was taken as 400 gal and damping ratio equals 0.05 under rare earthquakes. 
Table 2. Input earthquake waves

\begin{tabular}{|c|c|c|c|c|c|}
\hline No. & Earthquake Waves & Recording Station & Components & $\begin{array}{c}\text { Predominent } \\
\text { periods }\end{array}$ & $\begin{array}{c}\text { PGA } \\
(\mathrm{g} \\
)\end{array}$ \\
\hline 1 & $\begin{array}{c}\text { Imperial Valley } \\
1940 / 05 / 19\end{array}$ & 117 El Centro Array \#9 & EW & 0.52 & 0.31 \\
\hline 2 & $\begin{array}{c}\text { Cape Mendocino } \\
1992 / 04 / 25\end{array}$ & $\begin{array}{c}89486 \text { Fortuna-Fortuna } \\
\text { Blvd }\end{array}$ & FOR090 & 0.24 & 0.11 \\
\hline 3 & $\begin{array}{c}\text { Imperial Valley } \\
1979 / 10 / 15\end{array}$ & 412 El Centro Array\#10 & H-E10050 & 0.5 & 0.17 \\
\hline 4 & Kobe 1995/01/17 & 0 Takatori & TAK000 & 1.22 & 0.61 \\
\hline 5 & Wenchuan & Wolong & NS & 0.18 & 0.62 \\
\hline
\end{tabular}

Fig. 3 and Fig. 4 indicates the average inter-story drift angle of the two models in $\mathrm{X}$ and $\mathrm{Y}$ direction under five earthquake waves. Firstly, average inter-story drift angle of two models in two directions are less than 1/100, which satisfy the requirement of Chinese seismic code. Secondly, it can be seen that the inter-story drift angle of NBM is about $2.5 \%$ less than that of CBM in two directions. However, the control effects of inter-story drift angle are limited. The replaceable coupling beams actually dissipate a large amount of seismic energy, but the smaller stiffness of replaceable coupling beams may lead to the limited control effects of inter-story drift angle.

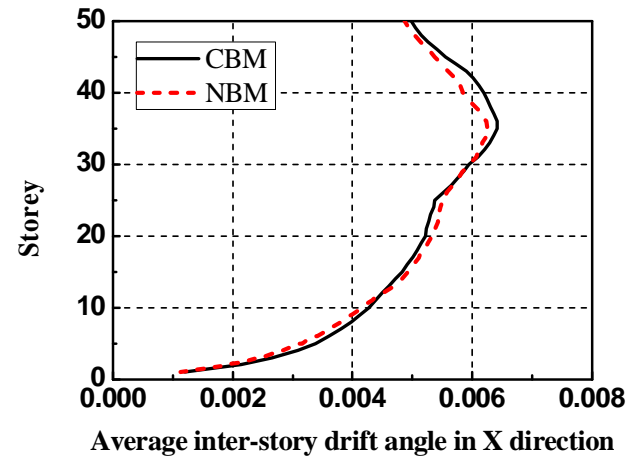

Fig.3. Average inter-story drift angle in $\mathrm{X}$ direction

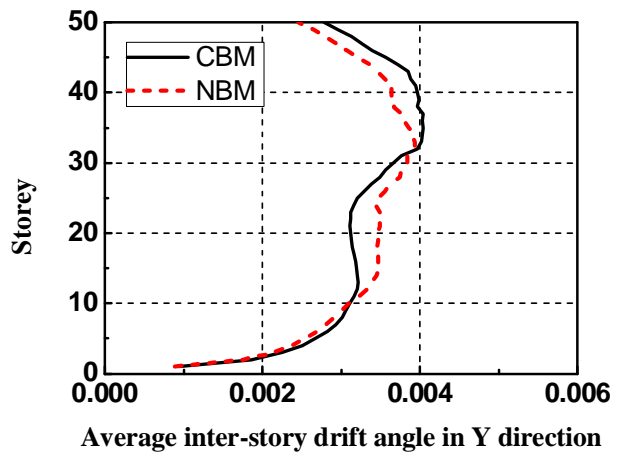

Fig. 4. Average inter-story drift angle in Y direction

In ABAQUS program, the damage index of concrete can be defined, so we can compare the damage of two models. Considering that the compression strain of shear wall are usually larger in these two locations, i.e., the toe of shear wall and 31-40 storey. Fig.5 shows the damage of RC tubes. From which we can find that the damage of NBM is less than CBM. Hence, the replaceable coupling beams can mitigate the damage of RC tubes. Here the damage control effects are defined by the following Eq. 1 .

$$
\xi=\frac{d_{N B M}-d_{C B M}}{d_{C B M}} \times 100 \%
$$



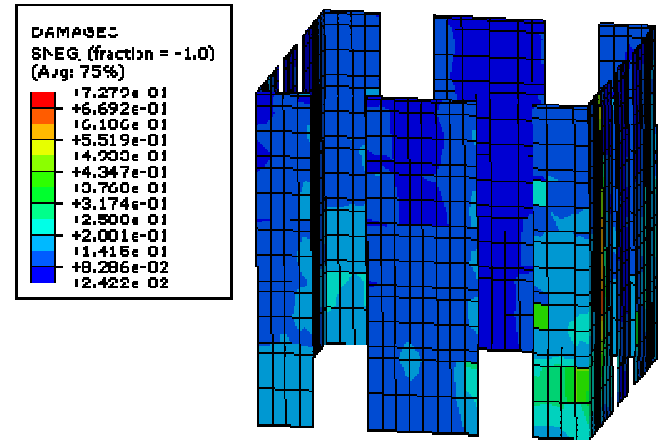

(a)Compression damage of 1-5 storey for $\mathrm{CBM}$

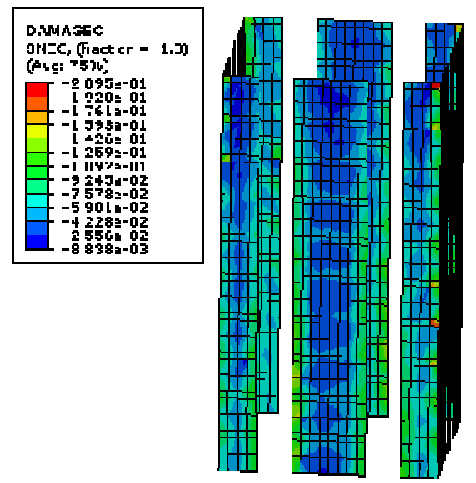

(c) Compression damage of 31-40 storey for CBM
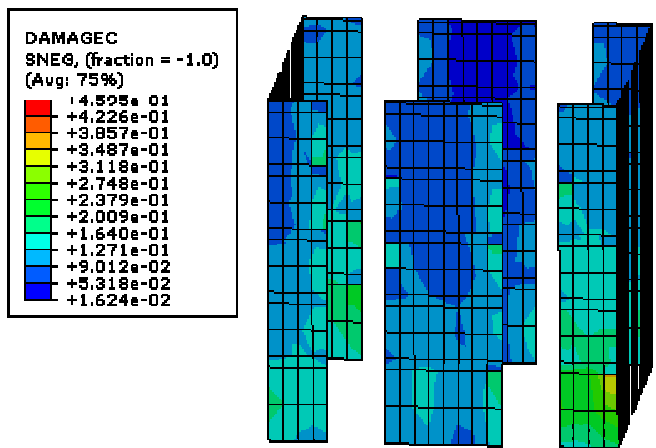

(b) Compression damage of 1-5 storey for

NBM
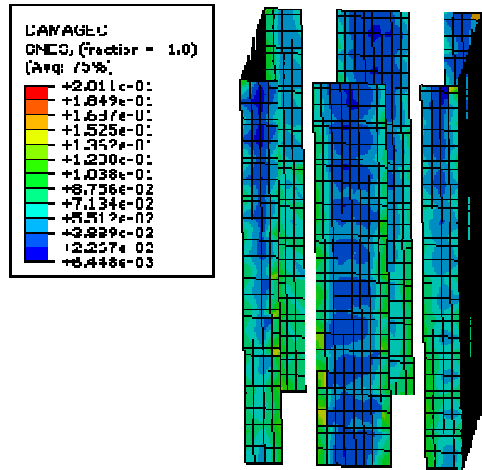

(d) Compression damage of 31-40 storey for NBM

Fig.5. Damage comparisons of two tubes

Table 3. Control effects of damage index

\begin{tabular}{|c|c|c|c|c|c|c|c|c|c|c|c|}
\hline \multicolumn{2}{|c|}{} & \multicolumn{2}{|c|}{ El Centro } & \multicolumn{2}{c|}{ Wenchuan } & \multicolumn{2}{c|}{ H-E10 } & \multicolumn{2}{c|}{ FOR } & \multicolumn{2}{c|}{ Takatori } \\
\hline \multicolumn{2}{|c|}{} & $\begin{array}{c}\text { Compression } \\
\text { damage }\end{array}$ & $\begin{array}{c}\text { Tension } \\
\text { damage }\end{array}$ & $\begin{array}{c}\text { Compression } \\
\text { damage }\end{array}$ & $\begin{array}{c}\text { Tension } \\
\text { damage }\end{array}$ & $\begin{array}{c}\text { Compression } \\
\text { damage }\end{array}$ & $\begin{array}{c}\text { Tensio } \\
\mathrm{n} \\
\text { damage }\end{array}$ & $\begin{array}{c}\text { Compression } \\
\text { damage }\end{array}$ & $\begin{array}{c}\text { Tension } \\
\text { damage }\end{array}$ & $\begin{array}{c}\text { Compression } \\
\text { damage }\end{array}$ & $\begin{array}{c}\text { Tension } \\
\text { damage }\end{array}$ \\
\hline \multirow{2}{*}{ CBM } & $1-5$ & 0.368 & 0.941 & 0.102 & 0.712 & 0.830 & 0.949 & 0.728 & 0.949 & 0.344 & 0.939 \\
\cline { 2 - 13 } & $31-40$ & 0.135 & 0.949 & 0.078 & 0.918 & 0.321 & 0.949 & 0.210 & 0.949 & 0.521 & 0.949 \\
\hline NBM & $1-5$ & 0.254 & 0.934 & 0.128 & 0.051 & 0.681 & 0.949 & 0.460 & 0.947 & 0.350 & 0.942 \\
\cline { 2 - 13 } & $31-40$ & 0.136 & 0.949 & 0.081 & 0.914 & 0.231 & 0.949 & 0.201 & 0.949 & 0.442 & 0.949 \\
\hline $\begin{array}{c}1-5 \text { control } \\
\text { effects (\%) }\end{array}$ & -30.94 & -0.69 & 24.51 & -92.81 & -17.98 & 0.00 & -36.87 & -0.17 & 1.89 & 0.27 \\
\hline $\begin{array}{l}31-40 \text { control } \\
\text { effects (\%) }\end{array}$ & 0.74 & 0.00 & 3.85 & -0.51 & -28.19 & 0.00 & -4.01 & 0.00 & -15.23 & 0.00 \\
\hline
\end{tabular}

From the Table 3, we can find the compression and tension damage of NBM is significantly smaller than that of CBM, especially in 1-5 storeys. Although NBM produced relatively large damage in 31-40 storeys, the damage of NBM is still smaller than that of CBM in these storeys. In summary, the replaceable coupling beams can effectively reduce the damage of the shear wall limbs.

We also compare the equivalent plastic strain of the replaceable coupling beams and conventional coupling beams respectively in CBM and NBM. From the Fig.6, it can be found that the damage of replaceable coupling beams in NBM mainly concentrated in the fuse while the other parts kept intact. In contrast, the conventional coupling beams in CBM produced integral damage, which indicated that it is difficult to replace the damaged conventional coupling beams in post-earthquake events. 


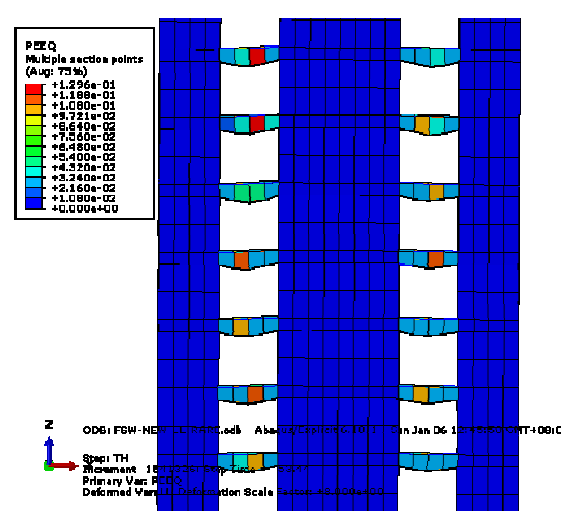

(a)CBM

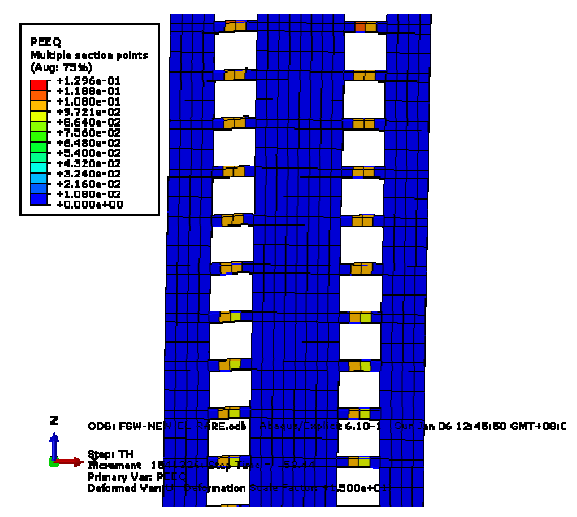

(b)NBM

Fig.6. Comparison of equivalent plastic strain

\section{Summary}

In this article, through the comparison of natural vibration period, inter-story drift angle and damage state of CBM and NBM under rare earthquakes, it was found that the inter-story drift angle and damage of the NBM was less than CBM. This indicated that the replaceable couplings beams can dissipate earthquake energy and reduce the damage of wall limbs. Moreover, in the replaceable coupling beams, the damage concentrated in energy dissipation devices, while the other parts of replaceable coupling beams kept intact, and it was convenient to replace damaged energy dissipation devices after the earthquake. However, further study should be conducted to improve the seismic performance of fuse, and strengthen the stiffness of replaceable coupling beams.

\section{Acknowledgements}

The financial supports from National Natural Science Foundation of China under Grants No.51408170 and the Midwest Key Areas Construction Project Plan of Hainan University under Grants No. ZXBJH-XK011 are gratefully appreciated.

\section{References}

[1] Paulay, T, Coupling beams of reinforced concrete shear walls, J.Struct.Div.ASCE. 97(1971), 843-862.

[2] Chung H. S., Moon B. W., Lee S. K., Park J. H., and Min K. W., Seismic performance of friction dampers using flexure of RC shear wall system, Struct. Design Tall Spec. Build. 18(2009) 807-822.

[3] Fortney, P. J., Shahrooz, B. M., and Rassati, G. A., Large-scale testing of a replaceable "fuse" steel coupling beam, J. Struct. Eng. 133(2007) 1801-1807.

[4] Teng, J., Ma, B. T., Li, W. H., Zhang, H., and Cao, D. X., Pseudo-static test for coupling beam damper of coupled shear wall structure, Journal of Building Structures. 31(2010) 92-100. (In Chinese)

[5] Xilin Lu, Yuanjun Mao, Yun Chen, et al, New structural system for earthquake resilent design, Journal of Earthquake and Tsunami. 7(2013):1350013-1-1350013-26.

[6] Lu Xilin, Chen Yun, and Jiang Huanjun, Experimental study on seismic behavior of "fuse" of replaceable coupling beam, Journal of Tongji University (Natural Science).,41(2013 )1318-1325+1332. (in Chinese) 
